\title{
A girl with Henoch Schönlein purpura associated with acute rheumatic fever and review of literature
}

\author{
Ebru Aypar ${ }^{1}$, Duygu Demirtaş ${ }^{2}$, Hayrettin Hakan Aykan ${ }^{1}$, Fehime Kara-Eroğlu ${ }^{3}$, Ali Düzova ${ }^{3}$ \\ ${ }^{1}$ Division of Pediatric Cardiology, ${ }^{3}$ Division of Pediatric Nephrology and Rheumatology, ${ }^{2}$ Department of Pediatrics, Hacettepe \\ University Faculty of Medicine, Ankara, Turkey. E-mail: aduzova@hacettepe.edu.tr \\ Received: 6th June 2017, Revised: 19th September 2017, Accepted: 30th October 2017
}

SUMMARY: Aypar E, Demirtaş D, Aykan HH, Kara-Eroğlu F, Düzova A. A girl with Henoch Schönlein purpura associated with acute rheumatic fever and review of literature. Turk J Pediatr 2018; 60: 576-580.

Henoch Schönlein purpura (HSP) with acute rheumatic fever (ARF) is a rare entity and only few cases have been reported so far. In all previously reported cases with HSP and ARF, patients initially presented with purpuric rash, arthralgia/arthritis, or abdominal pain and later diagnosed as ARF. We report an 11-year-old girl with features of both ARF and HSP. She initially presented with arthralgia and murmur. Echocardiography showed mild to moderate mitral regurgitation. Later, the clinical course was complicated by purpuric rash and abdominal pain. She was treated conservatively with IM penicillin, acetylsalicylic acid and oral prednisolone. Our patient is the first patient with HSP and ARF who initially presented with features of ARF. A review of literature revealed a limited number of cases of HSP associated with ARF (14 cases including the present case); and that the response to treatment in cases suffering from ARF associated with HSP was good; but one should also be aware of serious cardiac complications in HSP patients which may be fatal.

Key words: acute rheumatic fever (ARF), carditis, group A beta-hemolytic streptococcus, Henoch Schönlein purpura (HSP).

Henoch Schönlein purpura (HSP) is an acute, systemic, immune complex mediated, leukocytoclastic vasculitis characterized by purpuric lesions on the lower extremities and buttocks (100\%), abdominal pain (63-76\%), arthritis (65-84\%), and nephritis (37-44\%). ${ }^{1}$ Cardiac involvement is a very rare but often a life-threatening complication of HSP. In 1948, Gairdner described five children who developed HSP associated with recent group A betahemolytic streptococcus (GABHS) infection, two of whom also had signs of rheumatic carditis, and proposed a possible pathogenic role of GABHS in HSP. ${ }^{2}$ Patients with features of HSP and acute rheumatic fever (ARF) have been rarely reported as case reports in the literature. ${ }^{2-10}$ In all previously reported cases, patients initially presented with clinical features of HSP; purpuric rash, arthralgia/arthritis, or abdominal pain and diagnosed as ARF during the course. We report an 11-year-old girl who initially presented with arthralgia and rheumatic carditis and later developed purpuric rash and abdominal pain.

\section{Case Report}

An 11-year-old girl was admitted to our pediatric emergency department with complaints of chest pain and arthralgia lasting for 10 days. She reported fever and diagnosis of acute otitis media which was treated with oral amoxicillin-clavulanic acid a week ago. Past medical history was unremarkable. Physical examination revealed: body weight $52 \mathrm{~kg}$ (90-97 percentile), height $150 \mathrm{~cm}$ (50-75 percentile), body temperature $36^{\circ} \mathrm{C}$, heart rate 88 beats/min, blood pressure 110/60 $\mathrm{mmHg}$, respiratory rate $24 / \mathrm{min}$. She had $1 / 6$ degrees pansystolic murmur at cardiac apex. Other system examinations were normal. Electrocardiography (ECG) revealed first degree atrioventricular block. Laboratory examinations showed white blood cell count $15,300 / \mathrm{mm}^{3}$, hemoglobin $13.1 \mathrm{~g} / \mathrm{dl}$, platelets $414,000 / \mathrm{mm}^{3}$, 
erythrocyte sedimentation rate (ESR) $73 \mathrm{~mm} /$ hour (0-25), C-reactive protein $21 \mathrm{mg} / \mathrm{dl}(0-$ 0.8 ), anti-streptolysin $\mathrm{O}$ titer $1,615 \mathrm{IU} / \mathrm{ml}$ (0-200), serum creatine kinase/MB $28 \mathrm{ng} /$ $\mathrm{ml}$ (0-2.9), myoglobin 65.6 (25-51), troponin $\mathrm{T} 0.28 \mathrm{ng} / \mathrm{ml}$ (0-0.014). Serum biochemistry was normal. Throat, urine and blood cultures were negative. Echocardiography showed mild mitral regurgitation with posterolateral jet. Diagnosis of ARF was made according to revised Jones criteria. ${ }^{11}$ Acetylsalicylic acid (ASA; $3.5 \mathrm{~g} /$ day; qid) was given for mild carditis. The patient was started on IM penicillin prophylaxis (benzathine penicillin G; 1,200,000 Units, every 3 weeks). On the third day of hospitalization, she had abdominal pain and purpuric rash on gluteal region, thighs and upper arms. Urinalysis showed microscopic hematuria ( $\mathrm{pH} 6.5$, density 1010, glucose, ketone and nitrite were negative, microscopic examination showed 8 erythrocytes/high power field). Stool examination was positive for occult blood. Serum complement levels were normal [C3 $141 \mathrm{mg} / \mathrm{dl}$ (79-152), C4 $14 \mathrm{mg} / \mathrm{dl}$ (16-38)]. Serum Ig A was elevated: $582 \mathrm{mg} / \mathrm{dl}$ (82-453). Anti-nuclear and antids-DNA antibodies were negative. Abdominal ultrasonography was normal. The patient was diagnosed as HSP according to recent childhood vasculitis criteria. ${ }^{12}$ Follow-up echocardiography showed moderate mitral regurgitation, ASA was switched to oral prednisolone $(2 \mathrm{mg} / \mathrm{kg} /$ day, p.o., maximum $60 \mathrm{mg}$ /day) and given for three weeks, then tapered and ASA (3.5 g/day, p.o.) was started. During the follow-up, her chest and abdominal pain disappeared; acute phase reactants and cardiac enzymes returned to normal levels in a week, moderate mitral insufficiency regressed to mild insufficiency. Urinalysis and stool examination became normal. Follow-up examination at two months showed normal acute phase reactants and no mitral regurgitation. Informed consent was received from the family.

\section{Discussion}

ARF is an inflammatory disease that occurs in susceptible individuals following GABHS usually Streptococcus pyogenes infection, such as streptococcal pharyngitis or scarlet fever. Diagnosis of ARF is made according to revised Jones Criteria. Elevated ASO titers suggested a recent streptococcal infection in our patient.
HSP is an acute, systemic, immune complex mediated, leukocytoclastic vasculitis. Our patient was diagnosed as ARF according to revised Jones criteria ${ }^{11}$ and HSP according to recent EULAR/PRINTO/PRES Ankara 2008 (European League Against Rheumatism/ Paediatric Rheumatology International Trials Organisation/Paediatric Rheumatology European Society) definition for childhood vasculitis. ${ }^{12}$ According to this recent set of criteria a patient is classified as HSP in the presence of purpura or petechiae (mandatory) with lower limb predominance plus one of four criteria: (1) abdominal pain; (2) biopsy showing predominatly IgA deposition; (3) arthritis or arthralgia; (4) renal involvement as hematuria or proteinuria.

Although the role of GABHS infection in HSP is not clear, evidence of preceding infection with GABHS was reported in 18 out of 30 patients $(60 \%)$ with HSP. ${ }^{13}$ Eisenstein et al. ${ }^{6}$ proposed that the disease of these patients is unlikely to be due to a single immune mechanism but rather a consequence of parallel processes initiated by different GABHS antigens. Therefore, effective treatment of GABHS infection is crucial to prevent the possibility of both HSP and ARF.

Table I summarizes the clinical and laboratory features of the previously reported 13 cases and the present case. The median age at diagnosis of 14 cases (50\% female) was 11 years (range: 4-40 years); only one patient was above 18 years of age. Among the previous 13 cases with HSP and ARF, rheumatic complications developed between 3 days to 12 weeks following the appearance of the rash specific for HSP. On the contrary, in our case, rash and abdominal pain appeared 3 days after the diagnosis of ARF. Twelve (86\%) and eight (57\%) cases suffered from carditis and arthritis, respectively. Data for clinical and echocardiographic improvement was available for 9 cases; 8 and 7 cases showed clinical and echocardiographic improvement, respectively.

Cardiac involvement is a very rare but often life threatening complication of HSP. Heart involvement usually manifests as myocarditis as opposed to valvulitis. Myocarditis, myocardial ischemia, myocardial necrosis, arrhythmia related to vasculitic process and atrioventricular block have been described; in previously 


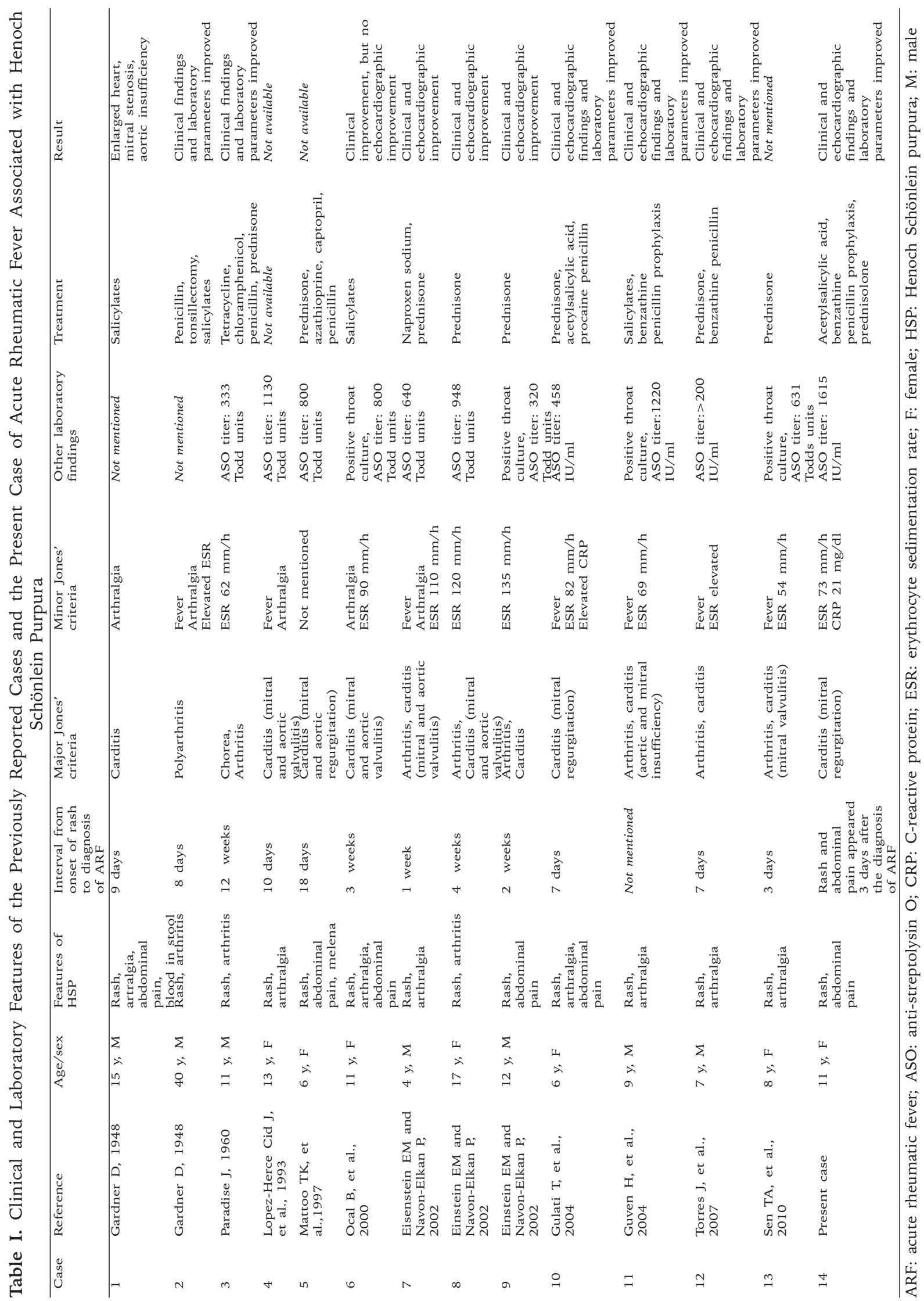


reported cases all patients were male, age ranged from 9 to 71 years. $8,14-16$ Most of these patients died due to cardiac involvement. Kereiakes et al. ${ }^{16}$ reported depositions of IgA and $\mathrm{C} 3$ in intramyocardial vessel walls in a patient without any cardiac symptoms, suggesting subclinical cardiac involvement in HSP. Kalyoncu et al. ${ }^{17}$ described a patient with HSP who developed pulmonary hemorrhage and active carditis related with previous rheumatic fever attack and died despite intensive treatment. Satoh et al. ${ }^{18}$ reported a patient with cardiac dilatation and left ventricular dysfunction. The histological examination showed myocardial damage, suggesting the invasion of vasculitis in HSP to the peripheral coronary arteries. Shin et al. ${ }^{14}$ suggest treatment with pulse methlyprednisolone and/or plasmapheresis in addition to classical therapy (salicylate and benzathine penicillin) of rheumatic fever, if serious cardiac involvement occurs in HSP patients.

Our patient had only valvulitis and did not have any serious myocardial involvement except transient cardiac enzyme elevation. The response to prednisolone and ASA treatment was excellent.

It can be challenging to say which disease has prior onset in these type of associations because two diseases have some similar clinical findings such as arthritis and arthralgia, especially if the interval between the two diseases is short. We do not have enough evidence to suggest echocardiography to all patients with HSP; but careful follow-up regarding cardiac auscultation may be helpful. Vice versa, skin rash and abdominal pain should be suggestive of HSP in patients with ARF, as in the presented case.

In summary, HSP and ARF association has been rarely reported. In all previously reported cases, the manifestations of ARF followed the diagnosis of HSP; we presented the first case in which ARF was the initial diagnosis. The response to treatment in cases suffering from ARF associated with HSP was good; but one should also be aware of serious cardiac complications in HSP patients which may be fatal.

\section{REFERENCES}

1. Brogan P, Bagga A. Leukocytoclastic vasculitis. In: Cassidy James T, Ross E, Ronald M, Carol B (ed). Textbook of Pediatric Rheumatology (6 $6^{\text {th }}$ ed). Philadelphia, PA: Saunders Elsevier, 2011: 483-497.

2. Gairdner D. The Schonlein-Henoch syndrome (Anaphylactoid purpura). Q J Med 1948; 17: 95-122.

3. Lopez-Herce Cid J, Cebrero Garcia M, Lopez de Sa E, Garcia de Frias E. Rheumatic fever associated with Schönlein-Henoch purpura. An Esp Pediatr 1993; 38: 568-570.

4. Mattoo TK, Al-Mutair A, Al-Khatib Y, Ali A, AlSohaibani MO. Group A beta-haemolytic streptococcal infection and Henoch-Schonlein purpura with cardiac, renal and neurological complications. Ann Trop Paediatr 1997; 17: 381-386.

5. Ocal B, Karademir S, Oguz D, Erdogan O, Oner A, Senocak F. Acute rheumatic carditis in Henoch-Scönlein purpura. Int J Cardiol 2000; 74: 97-98.

6. Eisentein EM, Navon-Elkan P. Acute rheumatic fever associated with Henoch-Schönlein purpura: Report of three cases and review of literature. Acta Paediatr 2002; 91: 1265-1267.

7. Gulati T, Kumar P, Dewan V, Anand VK. HenochSchönlein purpura with rheumatic carditis. Indian J Pediatr 2004; 71: 371-372.

8. Guven H, Ozhan B, Bakiler AR, Salar K, Kozan M, Bilgin S. A case of Henoch-Schönlein purpura and rheumatic carditis with complete atrioventricular block. Eur J Pediatr 2006; 165: 395-397.

9. Torres J, de Oliveira S, de Almeida R, Pelajo C, Sztajnbok F, Rodrigues MC. Acute rheumatic fever associated with Henoch-Schonlein purpura. Case report and review of the literature. Acta Reumatol Port 2007; 32: 377-380.

10. Sen TA, Kundak AA, Güraksın O, Demir T, Narcı A Acute rheumatic carditis associated with SchoenleinHenoch vasculitis. Anadolu Kardiyol Derg 2010; 10: 465-466.

11. Special Writing Group of the Committee on Rheumatic Fever, Endocarditis, and Kawasaki Disease of the Council on Cardiovascular Disease in the Young of the American Heart Association. Guidelines for the diagnosis of rheumatic fever. Jones Criteria, 1992 update. JAMA 1992; 268: 2069-2073.

12. Ozen S, Pistorio A, Lusan SM, et al; Paediatric Rheumatology International Trials Organisation (PRINTO). EULAR/PRINTO/PRES criteria for Henoch-Schönlein purpura, childhood polyarteritis nodosa, childhood Wegener granulomatosis and childhood Takayasu arteritis: Ankara 2008. Part II: Final classification criteria. Ann Rheum Dis 2010; 69: 798-806.

13. Robson WLM, Leung AKC. The frequency of preceding infection with group A beta-hemolytic streptococcus in patients with Henoch-Schonlein purpura. J Singapore Paediatr J 1993; 35: 168-172.

14. Shin JI, Kim JH, Lee JS, Kim DS, Choi JY, Sul JH Cardiac manifestations of Henoch-Schoenlein purpura: IgA mediated vasculitis or Rheumatic fever? Eur J Pediatr 2007; 166: 627. 
15. Osman A, McCreery CJ. Cardiac vasculitis in HenochSchonlein purpura. Circulation 2000; 101: E69-E70.

16. Kereiakes DJ, Ports TA, Finkbeiner W. Endomyocardial biopsy in Henoch-Schonlein purpura. Am Heart J 1984; 107: 382-385.
17. Kalyoncu M, Cakir M, Erduran E, Okten A. HenochSchonlein purpura: A case with atypical presentation. Rheumatol Int 2006; 26: 669-671.

18. Satoh M, Mikuniya A, Mikami M, et al. A case of Henoch-Schönlein purpura with myocardial complications. Kokyu To Junkan 1991; 39: 273-277. 